\title{
Effect of Calcium and Magnesium Addition on the Inclusions in the Cast Microstructure of HSLA Steel
}

\author{
Yan LIU ${ }^{1, a,{ }^{*}, \text { Kai WANG }}{ }^{2, b}$, Yang LIU ${ }^{2, c}$, Jian-Ming WANG ${ }^{2, d}$ \\ ${ }^{1}$ The Liaoning Provincial Key Laboratory of Advanced Materials \& Preparation Technology, \\ Shenyang University, Shenyang, 110044, China \\ ${ }^{2}$ School of Mechanical Engineering, Shenyang University, Shenyang 110044, China \\ aliuyanneu@163.com, bwkai1991@foxmail.com, cshendacaijialy@126.com, \\ dwjmlucky1979@163.com \\ ${ }^{*}$ Corresponding author
}

Keywords: Calcium, Magnesium, Cast Microstructure, Inclusions, HSLA Steel.

\begin{abstract}
A new technology to obtain a fine-structured and high-toughness HAZ of HSLA steel for high heat input welding is developed using metallurgical thermodynamics, physical chemistry of metallurgy and material processing methods synthetically in this study. A kind of HSLA steel is designed in this experiment. The thermal stability second phase particles which would not be dissolved or aggregated at high temperature will be expected by means of adding calcium and magnesium simultaneously into the steel in the form of Si-Ca alloy and $\mathrm{Mg}-\mathrm{Zr}$ alloy. The effect of calcium and magnesium addition on the distribution and composition of the inclusions in the cast microstructure of HSLA steel was analyzed. The results show that the distribution of the inclusions is more dense and uniform with respect to the raw steel, and the size of the inclusions is smaller than the ones in the raw steel after adding $\mathrm{Ca}$ and $\mathrm{Mg}$ elements simultaneously. Lots of $\mathrm{Ca}$ and $\mathrm{Mg}$ oxides and inclusions formed after pouring into ingots. The main components of the inclusions formed are $\mathrm{Al}_{2} \mathrm{O}_{3}-\mathrm{MnS}-\mathrm{CaO}-\mathrm{ZrO}_{2}-\mathrm{MgO}-\mathrm{SiO}_{2}$, and most $\mathrm{Ca}$ and $\mathrm{Mg}$ inclusions are spherical and ellipsoidal.
\end{abstract}

\section{Introduction}

The rapid development of the large steel structure brings a great opportunity for steelmaking industry. However, as the design requirements improve and the manufacturing technology of the steel structure advances, the requirements for the performance of steel plate which is used to fabricate the steel structure also improve continuously. The steel plate not only has the strength and toughness but also can withstand the high energy input welding. Therefore, a new technology to obtain a fine-structured and high-toughness HAZ is developed for the purpose of realizing excellent toughness in a HAZ of HSLA steel for high heat input welding using metallurgical thermodynamics, physical chemistry of metallurgy and material processing methods synthetically in this study. Calcium and Magnesium inclusions have high temperature stability, high melting point, ultra-fine, evenly distributed and controllable composition.

The experiment takes a kind of HSLA steel as the research object and analyses the effect of calcium and magnesium addition on the distribution and composition of the inclusions in the cast microstructure. The study can provide a reliable theoretical basis and technical support for the development and application of high heat input welding HSLA steel which has good strength and toughness. The study can reduce production costs and save social resources effectively. The research results can transform into productivity and create a new growth point for the national economy.

\section{Experiments}

\section{Experimental Materials}

A kind of HSLA steel is designed in this experiment. The components of the steel are obtained by smelting pure iron and adding the corresponding alloy. The components of pure iron and main alloy 
are shown in Tab.1.

Tab.1 Components of pure iron and main alloys (wt $\%)$

\begin{tabular}{ccccccccccccc}
\hline Alloy & $\mathrm{C}$ & $\mathrm{Si}$ & $\mathrm{Mn}$ & $\mathrm{P}$ & $\mathrm{S}$ & $\mathrm{Al}$ & $\mathrm{Fe}$ & $\mathrm{Ca}$ & $\mathrm{Mg}$ & $\mathrm{Zr}$ & $\mathrm{Ni}$ & $\mathrm{Cu}$ \\
\hline Pure & 0.0013 & 0.01 & 0.05 & 0.007 & 0.0044 & 0.0013 & 92.6 & $/$ & $/$ & $/$ & $/$ & $/$ \\
iron & & & & & & \\
$\mathrm{Fe}-\mathrm{Si}$ & 0.024 & 78.96 & 0.058 & 0.0093 & 0.0037 & 0.24 & 20.24 & $/$ & $/$ & $/$ & $/$ & 0.049 \\
$\mathrm{Si}-\mathrm{Ca}$ & 0.13 & 66 & $/$ & 2.6 & $/$ & 0.15 & $/$ & 31 & $/$ & $/$ & $/$ & 12 \\
$\mathrm{Mg}-\mathrm{Zr}$ & $/$ & 0.0053 & 0.0061 & $/$ & $/$ & 0.0053 & 0.029 & $/$ & 69.68 & 30.12 & 0.15 & 0.0014 \\
\hline
\end{tabular}

Calcium and Magnesium are added at the same time in the form of $\mathrm{Si}-\mathrm{Ca}$ alloy and $\mathrm{Mg}-\mathrm{Zr}$ alloy. Other alloys include electrolytic manganese (99.9\%), ferrovanadium (78.6\%), ferrotitanium (99\%), ferroniobium (65.6\%), ferronickel (78.6\%), ferrochromium (85.5\%) and molybdenum (76.3\%).

\section{Smelting Equipment and Process}

The directions of the microalloyed development in HSLA steel in every country throughout the world are as follows: (1) The obvious trend of carbon reduction presents. (2) The microalloy method combines with the thermo mechanical control process (TMCP). Use the composite microalloy $(\mathrm{Nb}, \mathrm{V}, \mathrm{Ti})$ to produce grain refinement and precipitation strength [1]. $\mathrm{Ca}$ and $\mathrm{Mg}$ metallic elements are added to form high smelting-point oxides, improving toughness and weldability of the steel plate. We designed a kind of HSLA steel, based on the above principle and absorbing predecessors's research experiences.

The experimental steel was smelted in BJ-VIM-5 vacuum induction melting furnace. The two furnaces in the test were accomplished in the order of no calcium and magnesium addition, $3 \mathrm{wt} \%$ $\mathrm{Ca}$ and $3 \mathrm{wt} \% \mathrm{Mg}$ addition at the same time. The steps of smelting the experimental steel are as follows. The operational data in the process of experiment is shown in Tab.2.

(1) The raw materials are put into the crucible. We must adopt the principle of tightness below and looseness above in order to make the smelting process go smoothly, when we add the raw materials. (2) After adding the raw materials, we begin to vacuumize. When the vacuum degree reaches $1.0 \times 10^{-2}$ $\mathrm{Pa}$, we begin to heat. (3) We turn up the power gradually in the heating process until the raw materials melt totally. (4) The argon gas as protective gas is filled in the whole smelting process to prevent the raw materials from oxidating. When the steel boils, we add alloy by a special method. (5) After adding alloy, we begin to stir it. After refinement for several minutes, we turn off the heating equipment and begin to pour. (6) After cooling for three hours, the casting mould is taken out.

Tab.2 Smelting operation data

\begin{tabular}{cccc}
\hline The heating time $(\mathrm{min})$ & The power $(\mathrm{kW})$ & $\begin{array}{c}\text { The voltage } \\
(\mathrm{V})\end{array}$ & $\begin{array}{c}\text { The melting situation of the } \\
\text { experimental steel }\end{array}$ \\
\hline 6 & 2.5 & 65 & $\begin{array}{c}\text { Become red at the bottom of it } \\
\text { Become red totally and the bottom } \\
19\end{array}$ \\
5 & 100 & melts \\
31 & 10 & 160 & The middle melts \\
39 & 13 & 185 & Most melts \\
43 & 15 & 200 & All melts and fill argon gas \\
53 & 17 & 220 & Begin to boil and add alloy \\
58 & 10 & 160 & Refine and pour \\
\hline
\end{tabular}

\section{Effect of Calcium and Magnesium Addition on the Inclusions Distribution in the Cast Microstructure of the HSLA Steel}

\section{The Morphology and Distribution of the Inclusions in the Cast Microstructure}

The scanning electron microscope (SEM) was used to analyze the morphology and distribution of the inclusions in the cast microstructure of the HSLA steel. The morphology and distribution of the 
inclusions in the cast microstructure of the 1-2\# experimental steel are respectively shown in Fig.1.

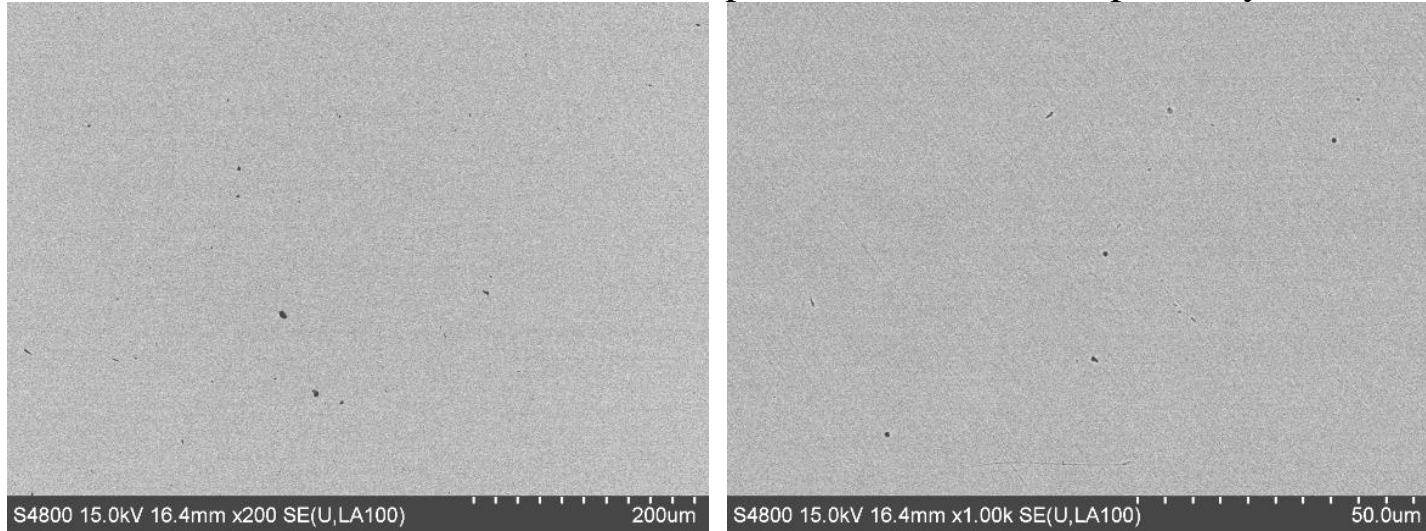

(1) the original steel of no adding $\mathrm{Ca}$ and $\mathrm{Mg}$

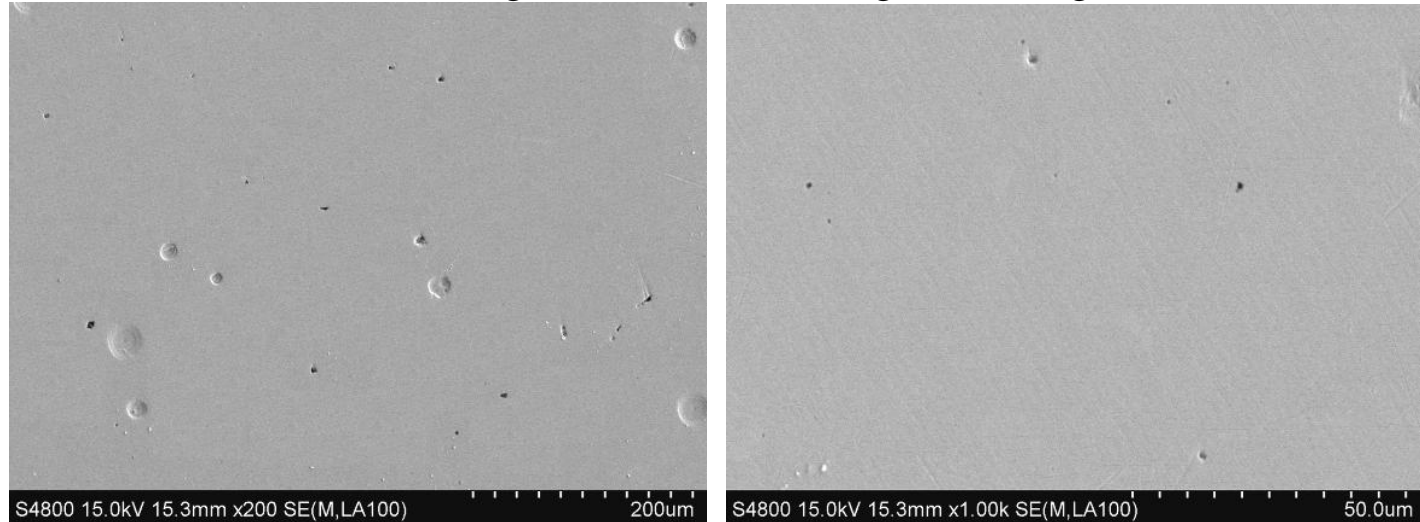

(2) the experimental steel of $3 \mathrm{wt} \% \mathrm{Ca}$ and $3 \mathrm{wt} \% \mathrm{Mg}$

Fig. 1 The morphology and distribution of the inclusions in each sample

\section{Results Analysis}

Through the contrast analysis to the morphology of the inclusions in the samples, We can find that after adding $\mathrm{Ca}$ and $\mathrm{Mg}$ elements, the distribution of the inclusions is more dense and uniform with respect to the raw steel, and the size of the inclusions is smaller than the ones in the raw steel. The major growth pattern of the inclusions is Oswald growth and maturity [2]. Under the condition of the given density and viscosity of molten steel, the larger the inclusion size is, the greater the probability of inclusions aggregation and growing up is [3].

\section{Effect of Calcium and Magnesium Addition on the Inclusions Composition in the Cast Microstructure of the HSLA Steel}

\section{The Morphology and Composition of the Inclusions in the Cast Microstructure}

The scanning electron microscope (SEM) and energy dispersive spectrometer (EDS) were used to analyze the morphology and composition of the inclusions in the cast microstructure of the HSLA steel. The results of the 1-2\# experimental steel are respectively shown in Fig.2.

\section{Results Analysis}

Fig.2 (1) is the figure of the electron backscatter diffraction (EBSD) and EDS in the raw steel, the inclusions are mainly the $\mathrm{TiO}_{\mathrm{X}}-\mathrm{Al}_{2} \mathrm{O}_{3}-\mathrm{SiO}_{2}-\mathrm{MnS}$ composite ones. Fig.1 (2) is the figure of the electron backscatter diffraction (EBSD) and EDS in $3 \mathrm{wt} \% \mathrm{Ca}$ and $3 \mathrm{wt} \% \mathrm{Mg}$ steel, the inclusions are mainly $\mathrm{Al}_{2} \mathrm{O}_{3}-\mathrm{MnS}-\mathrm{CaO}-\mathrm{ZrO}_{2}-\mathrm{MgO}-\mathrm{SiO}_{2}$. The study found that lots of $\mathrm{Ca}$ and $\mathrm{Mg}$ oxides and inclusions formed after pouring into ingots owing to the adding $\mathrm{Ca}$ and $\mathrm{Mg}$ elements at the same time. The distribution of the inclusions is homogeneous, the size of the inclusions is even small, and most $\mathrm{Ca}$ and $\mathrm{Mg}$ inclusions are spherical and ellipsoidal. The main components of the inclusions 
formed are $\mathrm{Ca}$ and $\mathrm{Mg}$ oxides and the composite inclusions, as well as the oxides, sulfides and composite inclusions of the other metallic elements.

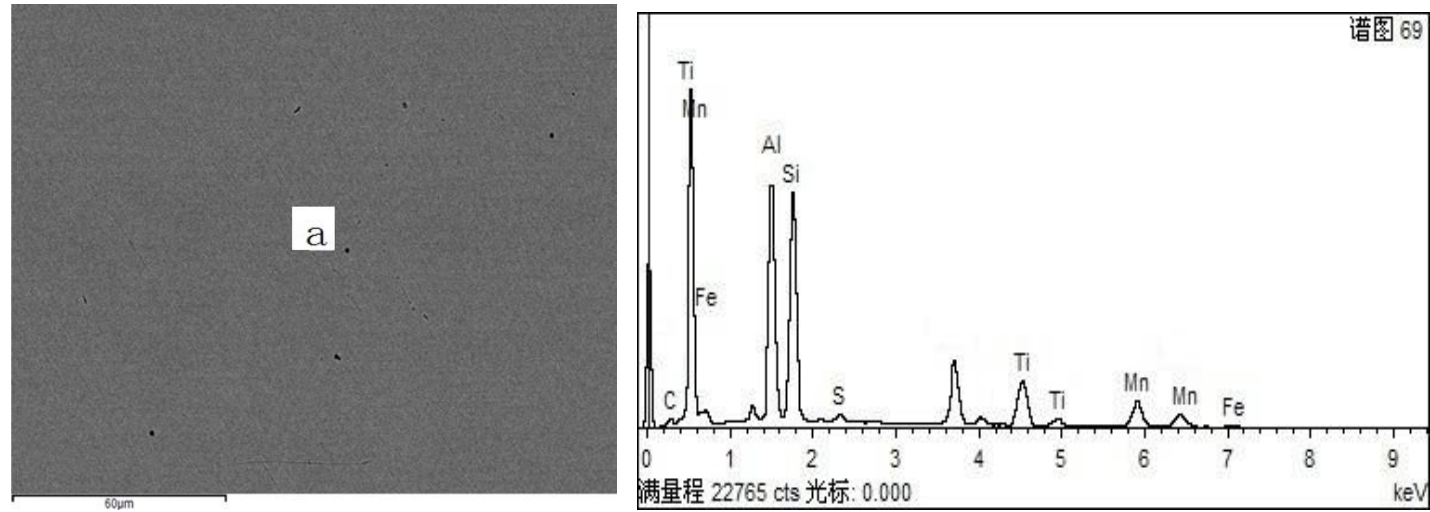

(1) the original steel of no adding $\mathrm{Ca}$ and $\mathrm{Mg}$
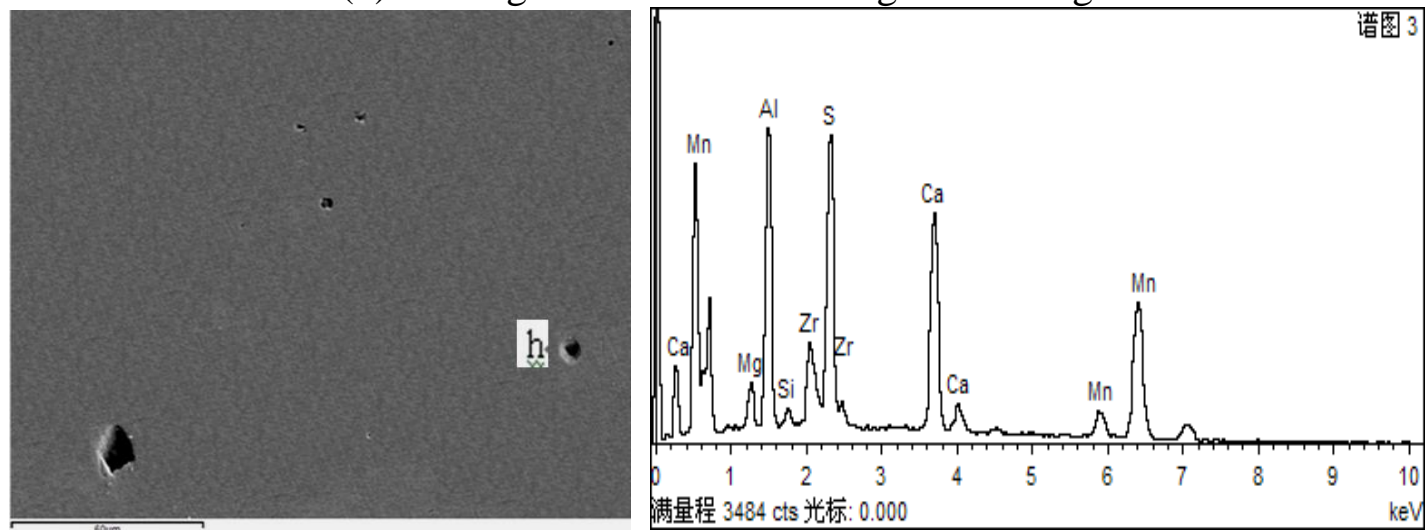

(2) the experimental steel of $3 \mathrm{wt} \% \mathrm{Ca}$ and $3 \mathrm{wt} \% \mathrm{Mg}$

Fig.2 The morphology and composition of the inclusions in each sample

\section{Conclusions}

Calcium and Magnesium elements were added into molten steel in the form of Si-Ca alloy and $\mathrm{Mg}-\mathrm{Zr}$ alloy in the experiment. The experiment takes a kind of HSLA steel as the research object and analyses the effect of calcium and magnesium addition on the distribution and composition of the inclusions in the cast microstructure of the HSLA steel.

(1) Through the contrast analysis to the morphology of the inclusions in the samples by SEM, we can find that after adding $\mathrm{Ca}$ and $\mathrm{Mg}$ elements simultaneously, the distribution of the inclusions is more dense and uniform with respect to the raw steel, and the size of the inclusions is smaller than the ones in the raw steel.

(2) Lots of $\mathrm{Ca}$ and $\mathrm{Mg}$ oxides and inclusions formed after pouring into ingots owing to the adding $\mathrm{Ca}$ and $\mathrm{Mg}$ elements at the same time. The main components of the inclusions formed are $\mathrm{Al}_{2} \mathrm{O}_{3}-\mathrm{MnS}-\mathrm{CaO}-\mathrm{ZrO}_{2}-\mathrm{MgO}-\mathrm{SiO}_{2}$, and most $\mathrm{Ca}$ and $\mathrm{Mg}$ inclusions are spherical and ellipsoidal.

\section{Acknowledgments}

This work was supported by the Liaoning Province Natural Science Fund Project (No. 2014020097), the Project for Liaoning Provincial Scientific Research in University of China (No. L2014475) and the Open Subject Fund of the State Key Laboratory of Rolling and Automation of NEU, China (No. 2009003).

\section{References}

[1]Y.T. Chen, A.M. Guo, P.H. Li, Nitride and carbonitride precipitation behavior in a Nb-Ti 
microalloyed extra low carbon HSLA steel, Heat Treatment of Metals. 32 (2007) 51-54.

[2]Z.H. Zhao, W.Q. Chen, H. Yuan, Effect of Boron on grain size of low-carbon steel iron and steel, Iron and Steel. 41 (2006) 67-71.

[3]L. Lin, Y.P. Bao, J.H. Liu, An analysis on modification effect of non-metallic inclusions in pipeline steel X80 by RH-feeding wire calcium treatment, Special Steel. 31 (2010) 49-54. 